
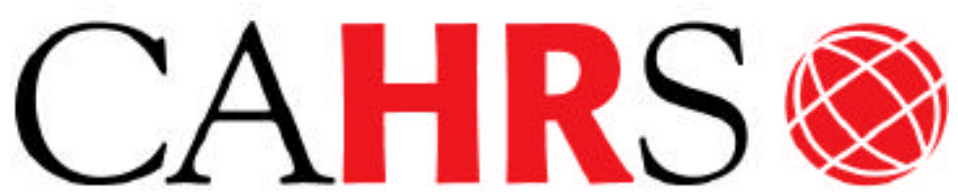

Center for Advanced Human Resource Studies
CAHRS / Cornell University 187 Ives Hall

Ithaca, NY 14853-3901 USA

Tel. 607 255-9358

www.ilr.cornell.edu/CAHRS/

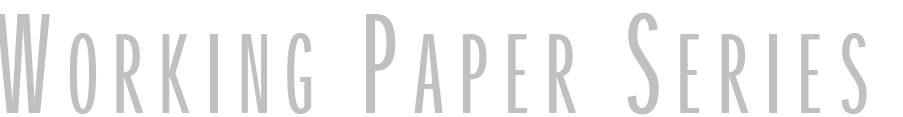

\section{Measuring Intellectual Capital: Learning from Financial History}

John W. Boudreau

Peter M. Ramstad

Working Paper $96-08$ 



\section{MEASURING INTELLECTUAL CAPITAL: LEARNING FROM FINANCIAL HISTORY}

John W. Boudreau and Peter M. Ramstad 


\section{MEASURING INTELLECTUAL CAPITAL: LEARNING FROM FINANCIAL HISTORY}

\section{John W. Boudreau and Peter M. Ramstad}

Emerging evidence from scientific studies and specific organizations suggests that how people are managed significantly affects organizational success, and that certain patterns of human resource activities are associated with financial performance. Most human resource (HR) and line managers, however, find existing measures of human and intellectual capital woefully inadequate. In this article, we suggest that designers of HR measurement systems can learn from the success of well-accepted measurement models in the financial and marketing arenas. We show that the historical development of these measurement systems suggests several lessons for the HR measures of the future. These lessons include articulating the links in the value chain, focusing on key organizational constraints, and using data to make "soft" intangible factors more tangible. (C) 1997 John Wiley \& Sons, Inc.

\section{Introduction}

Managing people well is a key to success and clearly is the job of every manager, not just the human resource (HR) "department." This fact is indicated by the public statements of top managers, the nature of current and future organizational changes, and emerging scientific research showing the HR practices and financial performance are related. The evolution of HR processes from administrative activities to strategic weapons is well underway, but a corresponding evolution of human resource measurement systems has not yet been seen. Compared to financial, marketing, and production measures, existing human resource measures are less systematic, less accepted, and less likely to guide key decisions. This is a paradox, considering the abundant existing and potentially available HR measures, including costs, process efficiency, activity levels, resource ratios, and customer or client ratings; yet these have not produced a widely accepted measurement system for HR. With increasing frequency managers ask the following question: "What is the HR measure that is the equivalent of market share, return on equity, or share price to help me gauge whether our human capability is increasing?" While no such "magic bullet" yet exists, we believe that clues to building future HR measures can be found by examining the measures used in other management areas.

This measurement dilemma is not new. In this article we propose that today's paradox regarding human resource and intellectual capital measurement parallels prior historical periods when measurement systems were about to change fundamentally. We show that each successful measurement evolution was characterized by certain key factorslinkages to value, constraints, and managing intangibility. We propose that the historical patterns in business success measures provide clues to developing systematic human resource measures of intellectual capital-the "scarce resource" of the future.
In this article we propose that today's paradox regarding human resource and intellectual capital measurement parallels prior historical periods when measurement systems were about to change fundamentally. 


\section{HR Measurement's Emerging Importance}

Human resources are every manager's job, but do managers have the measurement tools to do that job? Perhaps traditional financial tools are the answer. Judy Lewent, one of today's hottest" executives and Chief financial Officer of Merck \& co., says financial analysis should serve to encourage the right behaviors in people: "Finance departments can take the nuances, the intuitive feelings that really fine business people have and quantify them" (Nichols, 1994, p. 92). Yet Michael Hammer says:

The biggest lie told by most organizations is "people are our most important assets." Total fabrication. They treat people like raw material. If you're serious about treating people as an asset, we're looking at a dramatic increase in investment in them. (Lancaster, 1995, p. B-1).

If "intellectual capital" management is the key job of top organizational managers, dos HR measurement capture the "nuances" that Lewent describes? Do HR measures provide guidance to distinguish between organizations where people are valued and those that pay only lip service to investments in people? For this vision to be realized, top managers such as Lewent will require HR measurement systems that they understand and can use as readily as the familiar financial measures. The answer, however, is not simply to adopt financial measures as the ultimate HR measure. Obviously, so many factors affect financial measures that it may be impossible to use them to determine the impact of people management. Not so obvious is the fact that financial measures emerged from particular economic realities which may no longer apply.

The model of future organization structure, goals, and values is rapidly changing. This increasing rate of organization change also suggests the need for a new approach to HR measurement. No single model will apply, but some scholars have suggested that an appropriate metaphor may be a spinning top, built on a base of solid independent business, with stability provided by cooperation, teamwork, and planning; energy or "thrust" provided by management "vision and style"; and an organizational culture that prevents the parts from spinning off (Ghoshal \& Mintzberg, 1994). Buzzwords abound, as the business press states that survival depends on having organizations with strong "cultures" driven by leaders who relentlessly pursue a "vision" through "simple structures," that provide "world-class training," value "people skills," and foster "entrepreneurship" (Dumaine, 1994; Rau, 1994; Work in America Institute, 1993). What HR or intellectual capital measures capture the parts of the spinning top? To track such things as vision, culture, and entrepreneurship, clearly remains a challenge, but can such things be managed if they cannot be measured? Today's financial systems and embryonic HR measures seldom capture these concepts well enough to support managers' decisions.

There is no shortage of HR measures, as this special issue illustrates. Managers might track HR department costs and activity ratios (Fitz-enz, 1995); costs of behaviors such as turnover and absence (Cascio, 1991), audits of HR activities, and even the estimated dollar value of individual HR programs (Boudreau, 1988, 1991). With the abundance of potential HR measures, one might ask whether the measurement question has been solved. Yet, as our prior examples show, these existing metrics seem to fall short of producing the same sort of systematic and widely accepted measurement system that is found in the financial, marketing, and production areas of the organization. Even the concept of "human resource accounting" (Flamholtz, 1985) has not produced a set of generally accepted HR accounting principles. Human resource accounting concepts are valuable in identifying the historical and replacement costs of acquiring, developing and separating employees. The broader human resource accounting notion of "putting people on the balance sheet" by assessing their "asset value" is intriguing; however, measuring these concepts has proved elusive (Scarpello \& Theeke, 1989). One reason is the tendency to frame HR measures too much in terms of financial measurement systems, and not enough in terms of their ultimate purpose.

Though anecdotal, a recurring episode from our experience captures the dilemma. When trying to "develop methods to measure 
human resources," managers often initially say they just don't seem to have any good HR measures; yet, they are typically using many HR measures already (e.g., salary costs, separation rates, time to fill vacancies, absenteeism, attitudes, etc.). In fact, most organizations recently adopted sweeping changes in their HR measurements to address a perceived lack of "information." At this point, we ask these managers, "if you have all of these measures, why do you think you need more?" The answer is usually something like, "We're just not getting the support we want from line managers who think $\mathrm{HR}$ is too "soft,", or, "We just don't seem to be creating world-class HR systems." Thus, the fundamental question about HR measurement is not, "How to construct the best HR measure?" but "How to induce changes through HR measurement systems?" (Boudreau, 1995a, 1995b).

The value produced by HR measurements is in their effect on organizations (Boudreau, 1991). Understanding that effect requires considering how HR measures affect and enhance the capability of key constituents. Increasingly, one constituent-top line managers - shows behaviorally that managing people is critical. Jack Welch, Chief Executive Office (CEO) of General electric, says, "The only way I see to get more productivity is by getting people involved and excited about their jobs," and "anybody who gets this [CEO] job has got to believe in the gut that people are the key to everything... " (Tichy, 1993, pp.87, 88). Even with over 15,000 employees in Microsoft, Bill Gates still finds time to woo some senior engineers, and even experienced software developers go through five or six hours of intense interviews (Deutschman, 1994). Financial and other measurement systems are used by top managers because they assist in managing one key constrained resource-capital. Do current HR measurement systems actually inform the decisions of CEOs such as Welch and Gates? Typical HR measures such as costs per hire, HR activity levels, or HR budgets do not seem to capture the "involvement and excitement" that top managers strive to enhance in their people.

Imagine that in one year there is a celebration to commemorate the success of a new HR measurement. What will all the speeches be about? What will people celebrate? Answering these questions implies a very different approach to HR measurement research and practice. Perhaps current measures can be improved by examining the properties that made existing measurement systems so useful.

\section{Lesson \#1: Measures should Reveal Value Linkages}

We argue that one key to the emergence of new HR measurement systems is the concept of linkages. Figure 1 shows the idea graphically.

\section{Tracking What HR Does: Individual HR Activities}

For most HR organizations, the focus is on the top portion of Figure 1, "What HR Does." This includes the levels of HR activity, as well as the immediate results or reactions to HR programs. Measuring this level of HR is important, and one can demonstrate HR value with such measures. Many of today's organizations assess the value of outsourcing and downsizing by pointing to the costs saved by moving administrative activities out. HR activity levels can provide clues to the actual resources expended when compared to plans or budgets. Activity, however, does not equal impact. More frequently, managers are stating, "Show me how this HR activity causes something good to happen for our organization." A good case in point is the recent Fortune article (Stewart \& Martin, 1996) suggesting that many HR departments are merely collections of activities with little demonstrable link to organizational success.

\section{Tracking Business Success: Unit-Level Outcomes}

At the bottom of Figure 1 is the "bottom line" concept. Recent research has begun to track the associations between bundles of HR activities and unit-level financial performance. It appears that integrated human resource strategies may be even more lucrative than merely being the sum of the parts. Research shows that automobile assembly plants, steel 


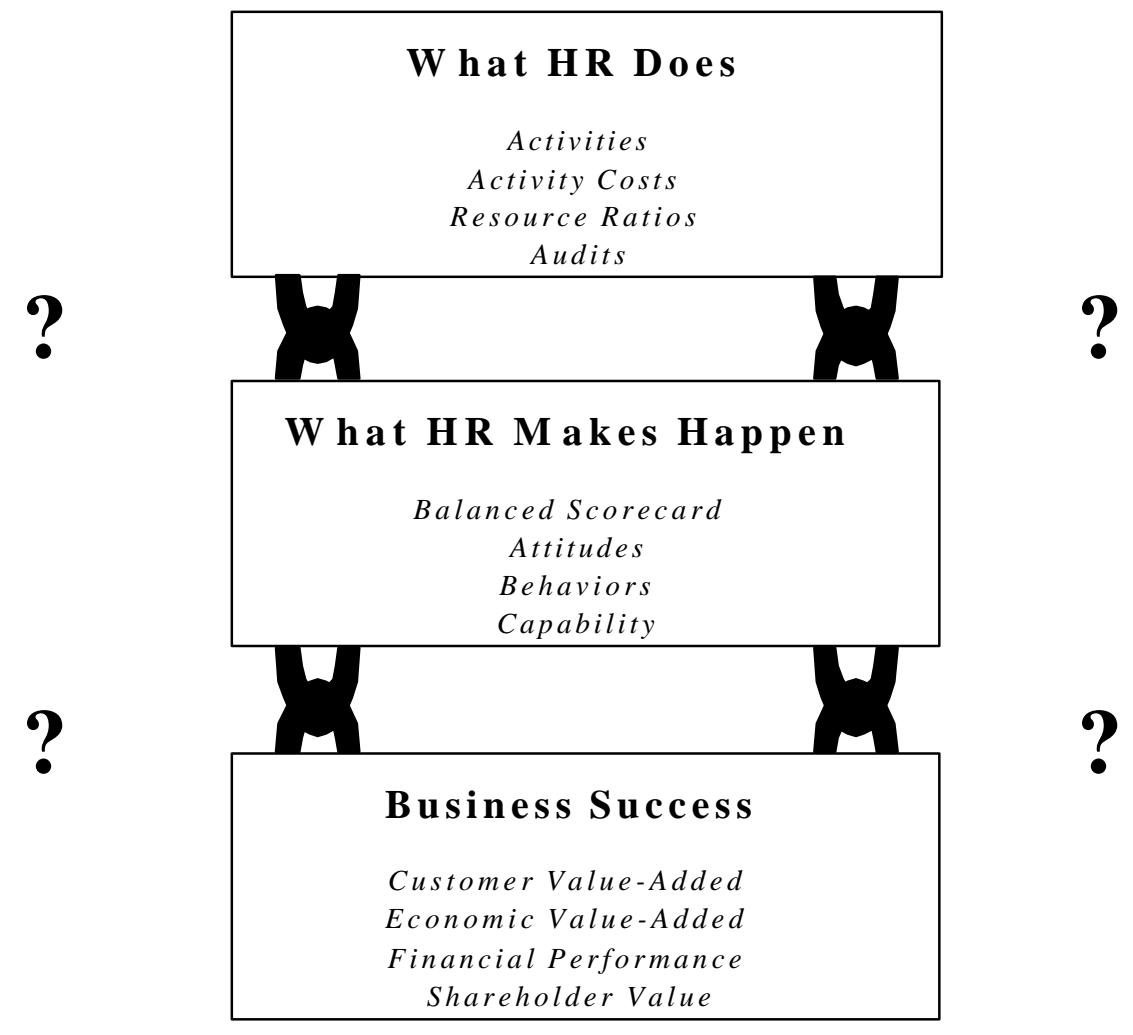

Figure 1. Linkages between the three levels of HR measurements.

minimills, and a diverse sample of U.S. firms perform significantly better when they combine flexible production arrangements, teambased work systems, and "sophisticated" or "high-commitment" human resource practices such as performance-based pay and extensive training (Macduffie, 1995; Arthur, 1994; Huselid, 1995). Thus, after organizations have implemented HR strategies, and then achieved financial results, it is possible to look back and discover relationships between the HR "bundles" and the overall performance. This result is important, and suggests that HR really does affect business success.

For managers to make investments in specific human resource programs, however, evidence of broad crossorganization effects may not be much help. The quotes from the CEO provide little guidance in determining whether it makes sense to invest in more expensive selection, training, or compensation programs. Evidence at the organizational level of the effectiveness of certain human resource practices and work designs may not provide the basis for deciding if a particular firm should invest in those practices. It is often difficult to control for the myriad other factors

that may have changed organizational-level results. Manager might well ask, "What do these practices really make happen to facilitate business results?"

\section{Defining the Middle Ground" Measuring Human and Intellectual Capital}

The middle box in Figure 1 describes where we believe future HR measurement systems must excel. This box contains the linkages between conducting the activities and achieving the business results. There are some measures at this level. Preventing safety or legal violations is frequently cited as a result of HR activities. Anecdotal evidence suggests such prevention can produce tangible results. Bridgestone/Firestone, Inc. was fined nearly $\$ 7.5$ million after a worker died as a result of safety violations (Salwen, 1994). For three months, among 440 unskilled 
blue-collar workers and low-level clerical employees in financial services, the costs of discretionary absence were estimated to be \$3,223 (Martocchio, 1992).

Can it be shown that HR activities generally affect outcomes like these? Psychological theories of motivation, attitudes, and learning suggest that organizations can significantly affect the capability and willingness of employees to behave in certain ways (Dunnette \& Hough, 1991). There is convincing evidence that workers respond in predictable ways when they are selected, paid, evaluated, and trained; and managers who understand these patterns can improve their ability to achieve goals through people. In fact, some industrial-psychology models even propose ways to translate the effects of human resource programs into dollars, so they can be compared with the anticipated dollarvalued return from other investments. These "utility models" suggest that the return on investments in people is often quite lucrative (Boudreau, 1991), but these models must make significant assumptions about the effects of HR programs.

A more compelling HR measurement model would gather evidence to show how HR activities lead to immediate effects on people, and then how these immediate outcomes combine to produce financial results. Such a system would provide managers with continuous leading indicators to determine how human capital was being improved by HR activities, and how those improvements lead to organizational success. The beginning of such measurement systems can be seen in the service industry. Sears, Roebuck and company created databases that included HR practices and employee attitudes, but also objectively measured employee behaviors that have been shown to link to business success. At Sears, the measures showed that leadership development led to improved employee attitudes. These attitudes were related to specific customerrelations behaviors such as meeting customers within one minute of their entering a sales area, greeting them with a smile, or calling attention to sale items. The Sears database then added rigorous financial measures of store success. Using these data, Sears showed that employee customer-relations behaviors lead to customer satisfaction, customer purchases, and word-of-mouth recommendations, which in turn lead to store revenue and profitability. Each link in the chain can be documented with solid data. Managers need not merely speculate that HR program effects translate to job behaviors, nor need they speculate about whether the job behaviors lead to organizational outcomes. The data are there, so the links are clear (Quinn \& Hartmann, 1996).

Notice how such a measurement system fundamentally changes the way HR decisions can be made. It is no longer necessary to rely solely on data about program costs or learning, and then subjectively extrapolate those outcomes to organization performance. Also, when organization performance seems associated with investments in HR programs, it is no longer necessary to speculate about whether the performance was the cause or the effect, or about how much of the improvement should be credited to the HR investments (Boudreau \& Berman, 1991). When the "middle ground" of Figure 1 is illuminated, the specific link can be discerned. In most organizations, the middle ground is mostly speculation based on the scantiest information. Measurement systems that illuminate the middle ground substitute evidence for speculation, and can produce better decisions as to how HR programs work together, and how much payoff HR investments really create.

The concept of linkage emerges as a key component of effective measurement systems that will create sustained behavior changes, better decisions, and something to celebrate about HR measurement. Now, consider other lessons more directly linked to alternative business measurement areas. Examining other areas of business measurement shows more clearly how the concept of linkages is key to HR measurement, but also how the concepts of constraints and intangibility have played a role in the evolution of successful measurement. 


\section{Lesson \#2: Focus on the Constraints}

Constraints are critical to measurement effectiveness. Consider the value of two different hypothetical (and physically impossible) machines. Both take air as the raw material input. One technology could extract oxygen from air and produce heat, the other could extract oxygen and hydrogen and produce clean water. What would the relative value of these machines be in Yuma, Arizona or Duluth, Minnesota? Clearly, if you are in Duluth, a ready supply of clean water is of almost no value. The only way it could create value is if it were cheaper than pumping it out of Lake Superior which is not very expensive in the first place. Even if the system was free, the maximum value that could be created is the cost of the local water bill, as water is already available in almost unlimited supply in Duluth. At the same time, a more effective home furnace is of little value in Yuma, Arizona. If the situation is reversed, however, tremendous economic value results, as Yuma has a shortage of clean water, and Duluth is significantly constrained by a lack of heat!

In the same way, otherwise identical HR programs can vary substantially in their economic impact, depending upon how they affect the different constrained and/or unconstrained resources of an organization. HR and intellectual capital measures, therefore, must include a thorough analysis of the constraints of the organization and the impact human assets have on those constraints. The way constraints lead to measures is illustrated by examining how the familiar financial capital measures evolved.

\section{How Capital Became Key}

For most of this century, businesses generally were managed as though capital was the most significant constrained resource. The vast majority of large organizations were engaged in the process of mineral extraction, manufacturing, distribution, or transportation. To be economically efficient at such processes, significant economies of scale were required, which in turn relied on large capital investments. Capital markets and the systems that supported them developed to meet the demand of these capitalintensive industries.

As a result, many of our business information and measurement systems focus on some form of capital return. When managers think of how they would quantify business success, they tend to focus on an equity measure, such as profits per share, return on investment, or stock price. In fact, many people believe that the very reason that firms exist is to maximize value per share. When Albert J. Dunlap took over as CEO of Scott paper Co. in 1994, he summed up his philosophy in two sentences: "Shareholders are the number one constituency. Show me an annual report that lists six or seven constituencies, and I'll show you a mismanaged company" (Birchard, 1995, p. 49). Many sophisticated measurement models, such as internal rate of return analysis (IRR), have developed to allow managers to maximize return on capital. Such models optimize capital decisions and, therefore, implicitly assume that capital is the constrained resource to be maximized. If an organization adopts programs only if they enhance the return on capital invested, however, the return on other resources (e.g., land, transportation assets, human capital) may not be optimized. For example, capital-based returns may be maximized by large layoffs because of significant labor cost savings, perhaps enhancing short-run return on capital; however, if the actual constraint is on human capital, layoffs designed merely to cut costs may exacerbate the unseen human capital constraint, causing long-term performance problems (Mabon, 1996; Milkovich \& Boudreau, 1997).

To understand how capital management systems developed, and to learn from their history, consider the economic and measurement systems which existed before the capital economy and markets developed.

Table I shows how each economic stage was characterized by certain 
TABLE1 Measurement Systems Evolved to Optimize the Critical Asset Required to Produce the Constrained Resource Associated with Each Economic Phase.

\begin{tabular}{llll}
\hline \multicolumn{1}{c}{$\begin{array}{c}\text { Economic } \\
\text { Phase }\end{array}$} & $\begin{array}{c}\text { Constrained } \\
\text { Resource }\end{array}$ & $\begin{array}{c}\text { Critical } \\
\text { Asset }\end{array}$ & \multicolumn{1}{c}{$\begin{array}{c}\text { Measurement/ } \\
\text { Information Systems }\end{array}$} \\
\hline Agricultural economy & Food & Crop land & $\begin{array}{l}\text { Weather records, land surveys, } \\
\text { agricultural universities }\end{array}$ \\
Trade economy & Distribution & Transportation & $\begin{array}{l}\text { Road maps, railroad timetables, time } \\
\text { zones }\end{array}$ \\
Capital economy & Tangible goods & Capital & $\begin{array}{l}\text { Security and Exchange } \\
\text { Commission/Financial Accounting } \\
\text { Standards Board, Moodys/Standard \& } \\
\text { Poors, Stock exchanges }\end{array}$ \\
& Intellectual & People & $\begin{array}{l}\text { The next generation of management } \\
\text { information systems will meet this } \\
\text { emerging need }\end{array}$ \\
& & & \\
& & & \\
& & & \\
& & & \\
\hline
\end{tabular}

constrained resources, which made certain assets critical, which in turn drove the development of measurements systems. Notice how ingrained these measurement systems become over time. A world without time zones is inconceivable, yet time zones and standards were developed in America only when America reached an era in which transportation assets had become a constrained resource. In fact, at one time there were 50 time zones (English, 1992) (perhaps similar to today's abundance of unrefined HR measures). If intellectual or human capital is becoming the constrained resource, human capital measurements should evolve. The key to human capital measurements usefulness is their ability to help optimize a critical constraint. As the bottom of Table I shows, organizational reality may have already moved beyond the point where capital is the key constraint.

\section{Capital May Not Be Today's Most Significant Constraint}

There is amounting body of evidence that, for a significant and increasing number of organizations, capital is not he most constrained resource. There is no better signal of this than the record-breaking series of company stock repurchase announcements, even when the stock is at or near record prices (Hamilton, 1996). It is appropriate to think of a stock repurchase as a layoff of cash. These organizations represent a variety of typically "capital intensive" industries and include General Electric, 3M, Sears, Citicorp, Caterpillar, DuPont, and Chrysler. Even some organizations that have posted significant losses, such as Digital Equipment Company, are repurchasing their shares.

Another sign of reduced capital asset constraints is the vast supply of financial capital available to firms without traditional business histories (e.g., sales, profits, etc.) but with significant intellectual assets, such as Netscape or Yahoo! (Baker, 1995). Finally, there is the emergence of measures such as economic value added (EVA) (Fisher, 1995). One key difference between EVA and the more traditional return on investment (ROI) is that EVA treats capital as a cost, just as any other input. EVA implicitly assumes that significant capital is available at a known cost, unlike ROI, in which the key objective is to maximize
There is a mounting body of evidence that, for a significant and increasing number of organizations, capital is not the most constrained resource. 
return on capital. Thus with EVA, capital must be used efficiently, but the objective is to maximize total value (net of the cost of capital), not to maximize rate of return on the capital. For example, many financial experts now believe that if the cost of capital for a firm is $18 \%$, it is better to deploy $\$ 5$ billion of capital at an average ROI of $24 \%$ (creating EVA of $\$ 300$ million) than to deploy only the first $\$ 2$ billion at an average ROI of $30 \%$, which creates EVA of $\$ 240$ million. $^{1} \quad$ Yet maximizing ROI favors the second option.

\section{If Not a Capital Constraint... Perhaps Intellectual Capital}

There is significant evidence that intellectual constraints are increasingly critical to organizational performance. Peter F. Drucker stated that knowledge id now fast becoming the sole factor of production, sidelining both capital and labor (Drucker, 1993). In the semiconductor industry, where the top ten companies recently had over 12,000 open positions, the predicted need for computer engineers and systems analysts in the next decade is over 700,000 (Dolan, 1996). It is the skills and knowledge of these professionals that create a fundamental constraint for this industry.

The shift from financial capital constraints to intellectual capital constraints can also be seen in the financial markets. Companies are repurchasing shares in record numbers, even as they are creating record numbers of new shares through employee stock option programs (Capell, 1996). When these stock options are "in the money" (and thus create value for employees), they reduce the returns that would otherwise have gone to those who provide tangible capital (nonemployee stockholders) in order to provide increased incentives and rewards to those who provide intangible capital (the employee stockholders).

\section{Historical Limits of Financial Measurements}

If intellectual capital is the key resource constraint, can existing financial systems adequately measure it, and thus become the appropriate HR measurement system of the future? The historical development of accounting systems shows why they are not sufficient; this development also shows how future HR measurement systems evolve. Accounting systems have been in existence for over 500 years; they serve a variety of purposes. The original purpose of double entry accounting systems was to provide shipping companies with an exchange control system for goods and cash. As these systems were developed internally, they were used exclusively as an internal management control device (Johnson \& Kaplan, 1987). The analogy in HR measurement would be measures used primarily by decision makers inside the HR function that provide cost control or activity monitoring, such as cost per hire, head count, turnover rates, and training activity.

As the accounting field matured, a more specialized area, financial accounting, emerged. Financial accounting was/is designed to provide the basis for investors to make capital decisions. Reliable data about the financial results of an organization are critical to the operation of efficient capital markets. In fact, the deliberate misrepresentation of accounting information as one securities abuse that hampered the development of the U.S. capital markets. The passage of the Securities Exchange Commission (SEC) Acts of 1993 and 1994 resulted in processes that markedly improved the information to the capital markets (Skousen, 1991), such as rigid accounting standards, registration and disclosure requirements, and broad independent audits of financial records. The key to financial accounting is the consistent application of accounting rules producing comparable information across organizations. This consistency facilitates capital allocation decisions by investors, reduces the cost of capital, and increases the capital supply. Thus, the imperative of financial accounting-to be above all 
consistent and reliable-historically restricted information to what could be objectively defined, measured, and verified. If the value of an item could not be independently assessed and verified, it was not considered an asset. These restrictions dramatically limited the ability to use financial accounting to make decisions regarding intellectual assets. Which seldom can be traced to objective arms-length transactions.

One can envision a similar evolution of HR measurements, in which certain measurement practices are applied across organizations so that reliable comparisons can be made. Examples include government reporting requirements such as Equal Employment Opportunity reports, safety reporting to the Occupational Safety and Health Administration (OSHA), etc. Such measurements apply across organizations and may serve regulatory needs, but they may not link to organizational performance. The lack of objective "ownership" in human assets had been a major stumbling block in applying accounting principles to human resources (Scarpello \& Theeke, 1989).

After financial accounting came the field of "finance," which focused on explaining and predicting the future capitalbased value of the firm. Finance used/uses accounting data, but combines them with other information to support internal decisions. This focus on internal constituents, and predication rather than description, frees financial models from slavish adherence to external reporting requirements. Finance models, however, focus on capital as the key variable to be optimized, which has historically provided limited information for decisions about people. For example, no matter how valuable the application of cross-term learning may be to enhancing future value, current financial models have not measurements system to capture such learning, except perhaps as a training expense. Recent SEC opinions have recognized the increasing importance of factors that significantly affect organizational value, but which traditionally have been excluded from financial reporting. Changes are being considered that would relax the objectivity constraint and allow nontraditional data that might not have satisfied historical standards of reliability and objectivity (Meyers, 1996). This may speed the development of financial models that include intangible assets, paving the way for finance to embrace elements of human capital measurement. Thus far the focus is mainly on factors such as patents and software, which much less emphasis on human capital.

\section{Implications for HR Measurement}

HR measurement systems should focus beyond simple descriptions of past activities, similar to traditional accounting. They should not be satisfied with measurement systems that merely satisfy regulatory requirements. Instead, HR measurement should adopt a predictive perspective, similar to finance. Developments in the financial field suggest that there is likely to be greater reliance on measures that capture intangible assets, and less stringent requirements that all measures adhere to rigid objective rules, which may lend support for HR measures that might have seemed too soft in the past.

\section{Lesson \#3: Intangibility Does Not Prevent Measurement}

The conclusion of "Lesson \#2" is that the key constrained resources of the future will reflect human capital, and that financial systems are evolving to recognize that. Such resources will be intangible, however, and not measurable with standard transaction-based accounting. Does this require a return to the old problem that human resources are too soft to measure and manage reliably? Again, existing organizational systems show that such intangibility need not prevent measurement and management. Here, we can learn a lesson from the field of marketing. Marketing is like HR in that its primary goal is to manage assets not fully recognized by accounting. What could be more human and intangible than brand
No matter how valuable the application of cross-team learning may be to enhancing future value, current financial models have no measurement system to capture such learning, except perhaps as a training expense. 
equity, customer loyalty, or relative position within the distribution channel. In addition, customers are a constrained resource for almost every organization. Marketing, thus, is a domain where intangible assets significantly affect firm performance; yet, marketing measures are well accepted and widely used by top decision makers. How did marketing do it?

Marketing measures vividly reflect the lessons of linkage and constraints. Marketing models link marketing activities to the future financial results of the firm. For example, many companies that market consumer products (including Proctor \& Gamble, M\&M Mars, Hallmark, etc.) have developed sophisticated systems to track how many retail outlets stock each item, the amount of the display (e.g., linear feet of shelf space), and the quality of the space (e.g., eye level is better than floor level). Distributors measure the shelf space allocation they receive (amount and location of shelf space) and attempt to maximize it. At the same time the retailers optimize the profits of a store by allocating space based on the gross margin produced by each shelf "resident." The key ratio is typically gross margin per shelf foot. Measurement systems for both the supplier and the retailer have focused on optimizing the same critical constraint-shelf space.

How do retailers know that shelf space is the key constrained resource, and what its relationship is to their performance? Careful model building and data gathering have shown the linkage between shelf space and such intangibles as customer brand awareness, "impulse" buying behavior, and repeat purchases. As a result, the models predict how current change in display space and location will result in future period sales. Shelf-space data provide a great deal of insight into the revenue stream, the earnings stream, and ultimately the value of the company. The key is to demonstrate, with hard data, the "intangible" linkages that at first existed only in the minds and experiences of salespeople, advertising managers, and customers. Recognition of constraints and the empirical description of linkages produced a marketing measurement system that transforms intangibles into useful managerial information.

Such data-based models help line managers and the capital markets understand the value of marketing concepts such as shelf space, spokesperson popularity, and slogan effects, financial markets react to them before they appear in the accounting figures. Thus, while marketing expenses are recorded in the current period, financial markets reflect the intangible future value inherent in significant achievements or changes in relative market position. For example, research shows a statistically significant increase in stock price after the public announcement of the intent to introduce a new marketing slogan (Mathur \& Mathur, 1995) or popular spokesperson (Agrawal \& Kamakura, 1995). Despite the imperfections of the data, and the intangibility of ideas such as reactions to slogans and spokespeople, marketing measures routinely are used to guide decisions about organizations. One reason is that marketing focuses on constraints and uses linkages to make the intangibles more measurable and thus more useful.

\section{Applying the Lessons to Human Resource Measurement}

To illustrate how these lessons can be applied to human capital, consider the staffing dilemma faced by fast-growth companies such as Netscape. These companies must develop new software concepts and products at a feverish pace to achieve or maintain their dominance in the market. They frequently hire hundreds of people into key jobs such as computer programming (currently, Java language programmers are a very hot commodity). On the surface, the constrained resource seems to be hours of programming effort, so responsive measurement systems focus on how quickly the organization can get programmer "bodies in the door." Many "standard" HR measurement systems would still estimate cost per hire, but costs are not the key measure because cost does not constrain the organization from achieving its goals. Even applicant quality is not an 
immediate constraint, beyond minimal ability to program in the appropriate language. On the face, it appears that this is a situation in which an HR measure (hiring speed) satisfies lessons of constraints, value linkage, and making an intangible (hiring sped) an understandable factor in decisions.

However, this idea has broader implications. These new programmers will eventually become long-term employees. Their future value may depend less on their ability to program in today's "hot" language and more on their ability to adapt quickly to the next breakthrough. Does today's hiring speed signify adaptability? If the real constraint is adaptability, it may well be appropriate to sacrifice speed today to identify and hire more adaptable programmers. The better HR measurement system might track mental abilities, flexible behaviors, or even personality traits associated with adaptability to change. These are intangibles, but by gathering data to show how they are associated with adaptability and programmer success, tangible business results become linked to the "intangible" concept of adaptability.

Thus, establishing linkages, focusing on constraints, and accepting intangibility historically have led to the development of new and useful measurement systems, and these examples showed how these lessons can be applied to measures of human and intellectual capital. Several recommendations emerge from these linkages.

\section{Recommendation \#1: Build on the Value Chain}

One way for HR to be a "business partner" is for HR managers and their constituents to truly understand the value chain and what it reveals about key constraints. This goes far beyond the ability to read and analyze a balance sheet or income statement. It means articulating links between what happens with the organization's people, and the operational and financial outcomes produced. A first step in measurement is to ask leaders, "what are the obstacles that must be overcome to reach your goals?" For example, consider companies that manufacture custom components which are then integrated into products produced by other manufacturers. Examples could include making dashboards for automobiles or custom processors for video games. A critical link in the value creation process is working with potential end users on product designs to ensure the company's product is included in the end users' final specifications. HR measures that merely track staff costs in manufacturing processes, the number of product designers, or even the technical qualifications of the company's employees will not reflect this key constraint. More appropriate measures might be the amount of time the company's designers spend assisting customers with their design problems, or the knowledge of company designers regarding customer goals and objectives. In companies such as GE, even the HR function is measured in part by the frequency with which customers and suppliers participate in internal training programs (such as "Work Out" or "Change Management").

\section{Recommendation \#2: Search for the Constraints}

One HR measurement system will not fit all situations. For HR measures to create change, they must identify and alleviate critical constraints. Though most financial measurement systems reflect capital as the key constraint, intellectual capital may be the key future constraint. With the value links identified, HR measurement designers should identify which human elements can alleviate the obstacles to reaching goals. When managers are asked, "What are the key business constraints?", they will seldom answer in terms of human resource measures or programs. It is rare for a line manager to say "My business success depends on training costs going down by $20 \%$." More typically, they answer in terms of what they know best-the business.

For example, in many organizations managers will say that a key future constraint is their ability to gather market intelligence and then deploy it quickly in the form of new products. What are the 
human capital linkages? Many successful HR functions have realized that the key human resource in such endeavors is salespeople. Current HR policies and measures, however, do not emphasize the market intelligence constraint; they focus instead on sales activity as the key constraint-providing incentives to sell, training to sell, and culture that treats customers as "targets." In successful firms, savvy HR organizations redefine this business problem to focus on how salespeople can effectively gather and then help deploy market information. Sales people formerly motivated and trained to redirect customer attention away from product flaws are now encouraged to engage customers in discussions about what is wrong and how it can be improved. They are paid, trained, and selected for their ability to listen to this information, communicate with internal product and marketing design teams, and then close the loop with customers as the improvements are made. HR measures that formerly focused on sales levels and incentives now focus on new ideas, effective teamwork, etc. By first searching for the business constraint, and then working backward through the linkages from that constraint to human elements, one can identify ways to measure the intangible, yet vitally important, human elements in business success.

\section{Recommendation \#3: Use Data Models, Even if the Data Are Imperfect}

Both financial measurement and marketing measurement do not require perfectly objective information. In fact, their evolution shows that they began with very imperfect data, but with very coherent models of the value linkage. These models guided data gathering. More data made the models more precise and credible, and the refinement process continued. Today both finance and marketing measurement systems embody measurable concepts that are linked empirically to valued outcomes. For HR, the lesson is to develop explicit working models that reflect constraints and linkages at the design stage of HR measurement. The temptation to measure what is available can actually work against the growth of useful measures, if what is available is not linked to the key value constraints.

For example, the four levels of training evaluation are well known (Kirpatrick, 1994). The fourth level is results, but this level is seldom measured because by the time a training program is completed and ready for evaluation, it is often difficult to discern the independent effect of that program on unit-level outcomes. An explicit value model, however, would specify the links among training activities, employee responses, employee behaviors, and the results they produce. With such a model, it is possible to track training effects more explicitly and eventually to show, with data, how training leads to Stage 4 results. The issue is not so much how to evaluate programs after the fact, but how to design measures that are integrated into the fundamental design and purpose of the HR program.

In the beginning, this will require making assumptions where data are unavailable; then, these assumptions can be tested. Just as there may be uncertainty as to the effects of a new product or financial instrument in marketing and finance, there may be uncertainty about a particular linkage in HR. Perhaps HR can adopt techniques from marketing and finance such as redefining the question to determine what is the minimum threshold effect necessary to achieve a certain goal (such as return on investment). Boudreau (1988) proposed break-even analysis as a method for calculating such minimum thresholds; Monte Carlo simulations can also model uncertainty (Rich \& Boudreau, 1987). Initially, such models may have more assumptions than data, but over time the linkages and constraints can be tested, essentially filling in the HR measurement models similar to the contents of financial and marketing models. In the example from Sears, assumptions about linkages between associate behaviors, customer reactions, and revenue were made; and a model was built. Then, using data, the 
linkages were confirmed and refined, resulting in a highly credible and supportable model for measuring and tracking HR effects. Building models also engages line managers and other staff in HR measurement design, a critical factor if HR measurement systems are to tap the diverse sources of data that will be needed.

\section{Recommendation \#4: Measure Even the Easy Wins}

Some HR activities are so inexpensive or so obviously effective that they require very little measurement to conclude that they address key constraints and have clear links to business outcomes (Boudreau, 1991). Often such easy wins are not closely evaluated or measured because the decision is so easy; however, they offer fertile ground to test and refine HR measures. For example, separation or turnover costs have long been measured by organizations. They are often reported with no real link to HR programs; when linked to effective HR activities, however, they can help demonstrate the connection between HR and results that addresses key constraints. For example, at Corning Glass Works, when the training director committed to a $30 \%$ return on investment for orientation training, he demonstrated that return by carefully tracking separations before and after the orientation, discovering how many fewer separations occurred among those receiving the training, and then calculating the saved costs of separations associated with those avoided separations (Lang, 1991). The numbers were not perfect, but the value model was clear and convincing. Even a "sure thing" should be measured to test and refine HR measurements, so that they become more precise, credible, and useful for more intangible outcomes in the future.

\section{Conclusion}

The importance of people in organizations is well accepted, but systems for measuring the impact of investments I people remain largely undeveloped, certainly only a pale shadow of the more seasoned models used to track financial and capital resources. The history of financial measurements as well as their fundamental premises help discern the beginnings of a system of HR measurement. The lessons suggest that HR measurement quality will be driven not simply by the particular HR measurements, but by their ability to inform and affect decisions (Boudreau, 1988). To affect decisions, such systems must reflect the key linkages between HR activities and valued outcomes; they must illuminate the middle ground. Future HR systems must focus on how human resource investments affect significant organizational constraints in the value creation process, rather than simply on the level or volume of expenditures on HR management programs. Such systems will always be somewhat imprecise, but this imprecision can be greatly reduced by careful attention to program design, evaluation, and the use of modeling tools to quantify and make explicit the riskiness in HR assumptions. In the end, there is no reason why HR measurement systems cannot be as credible as their financial counterparts. Indeed, such systems may well become even more essential in meeting future organizational challenges, with the increasing importance of human factors in future organizations. Our hope is that by focusing attention on the reasons behind the development of existing measurement systems, future managers and researchers may find principles to guide the development of systems for measuring human and intellectual capital. 
John W. Boudreau is Associate Professor of Human Resource Studies, and Director of the Center for Advanced Human Resource Studies at Cornell University. His research includes human resource (HR) management decision making; HR information systems; applications of economics, accounting, and financial theories to HR decisions; computer applications to HR management decisions; organizational staffing; and HR strategic planning. Professor Boudreau has consulted and designed seminars in HR Management Decision Making. HR Metrics, and Human Resource Information Systems for companies such as GE, Mobil, IBM, Eastman Kodak, Chevron, NYNEX, and ScheringPlough. His research and consulting spans the U.S., Asia, Australia, and Europe. He founded and coordinates HRNET, a leading Internet HR discussion group.

Peter M. Ramstad is Chief Financial Officer of Personnel Decisions International (PDI). Over the last seven years, Mr. Ramstad has held various financial, systems management, and business planning positions within PDI. As a result, he has had many opportunities to work firsthand with the core tools and techniques of assessment, development, and organizational effectiveness. Prior to joining PDI, Mr. Ramstad was a partner with a major public accounting firm focusing on financial, operational, and systems consulting in high tech and service environments. Mr. Ramstad has undergraduate degrees in Math and Accounting with minors in Economics and Computer Science, and significant graduate studies in Economics, mathematics, and Accounting. He is a Certified Public Accountant and a Certified Management Accountant, and a member of the AICPA. 



\section{REFERENCES}

Agrawal, J. \& Kamakura, W.A. (1995). The economic worth of celebrity endorsers: An event study analysis. Journal of marketing, 59, 56-62.

Arthur, J.B. (1994). Effects of human resource systems on manufacturing performance and turnover. Academy of Management Journal, 35, 670-687.

Baker, M. (1995). Technology investors fall head over heels for their new love. The Wall Street Journal. August 10, A1.

Birchard, B. (1995). How many masters can you serve? CFO, July 48-54.

Boudreau, J.W. (1998). Utility analysis. In Dyer, L. (ed.), Human resource Management: Evolving roles and responsibilities. ASPA/BNA Handbook of Human Resource Management. Washington, DC: Bureau of National Affairs, Vol. 1, pp. 1-186

Boudreau, J.W. (1991). Utility analysis for decision in human resource management. In Dunnette, M.D. \& Hough, L.M. (eds.), Handbook of Industrial and Organizational Psychology. $\left(2^{\text {nd }}\right.$ ed.), Vol. 2. Palo Alto: Consulting psychologies Press, pp. 621-745.

Boudreau, J. (1995a). Future utility analysis research: Continue, but expand the cognitive and strategic focus. Paper presented at the National Meeting of the Academy of Management, August, Vancouver, Canada.

Boudreau, J. (1995b). "So What?": HR measurement as a change catalyst. Paper presented at the National Meeting of the Academy of Management, August, Vancouver, Canada.

Boudreau, J.W. \& Berman, R. (1991). Using performance measurement to evaluate strategic human resource management decisions: Eastman Kodak's experience with profit sharing. Human Resource Management, 30, 393-410.

Capell, K. (1996). Options for everyone. Business Week, July 22, 80-84.

Casico, W.F. (1991). Costing human resources, $3^{\text {rd }}$ Ed. Boston, MA: Kent Publishing.

Deutschman, A. (1994). The managing wisdom of high-tech superstars. Fortune, October 17, 197205.

Dolan, K. (1996). Help wanted: urgent! Forbes, October 7, 18-20.

Drucker, P. 91993). Post-capitalist society. New York: HarperBusiness.
Dumaine, B. (1994). Why great companies last. Fortune, January 16, 129.

Dunnette, M.D. \& Hough, L. (1991). Handbook of industrial \& organizational psychology. Palo Alto, CA: Consulting Psychologists Press, Vol. 2.

English, V.H. (1992). Time zone. In The Encyclopedia Americana, International Edition. Danbury, CT: Grolier Incorporated, Vol. 26, pp. 758-759.

Fisher, A.B. (1995). Creating stockholder wealth. Fortune, December 11, 105-106.

Fits-enz, J. (1995). How to measure human resources. New York: McGraw-Hill.

Flamholtz, E.G. (1985). Human resource accounting. San Francisco, CA: JosseyBass.

Ghoshal, S. \& Mintzberg, H. (1994). Diversification and diversifact. California Management Review; 37, 8-27.

Hamilton, W. (1996). Investor's Corner: Econ 102-Buybacks, a source of demand. Investor's Business Daily; February 14, p. A1.

Huslid, M.A. (1995). The impact of human resource management practices on turnover, productivity and corporate financial performance. Academy of Management Journal, 38, 635-672.

Johnson, H.T. \& Kaplan, R.S. (1987). Relevance lost. Boston, MA: Harvard Business School Press.

Kirkpatrick, D.L. (1994) Evaluating training programs: The four levels. San Francisco: Berrett-Koehler.

Lancaster, G. (1995). Re-engineering authors reconsider re-engineering. The Wall Street Journal, January 7, B1.

Lang, S. (1991). Corning's blueprint for training in the 90's. Training. July, 3336.

Mabon, H. (1996). The cost of downsizing in an enterprise with job security. Journal of Human Resource Costing and Accounting, 1, 35-62.

MacDuffie, J.P. (1995). Human resource bundles and manufacturing performance: Organizational logic and flexible production systems in the world auto industry. Industrial and Labor Relations Review; 48, 197-221. 
Martocchio, J.N. (1992). The financial cost of absence decisions. Journal of Management, 18, 133-152.

Mathur, L.K. \& Mathur, I. (1995). The effect of advertising slogan changes on market values of firms. Journal of Advertising Research, January/February, 59-65.

Milkovich, G.T. \& Boudreau, J.W. (1997). Human resource management. Burr Ridge, IL: Richard Irwin.

Myers, R. (1996). Getting a grip on intangibles. CFO, September, 49-54.

Nichols, N. (1994). Scientific management at Merck: An interview with CFO Judy Lewent. Harvard Business Review, January-February, 89-99.

Peterson, T. (1996). Closing Bell: Fat City. Business Week, May 13, p. 54.

Quinn, R. \& Hartman, S. (1996). Breaking the code: The Sears strategic implementation process. Presented to the Center for Advanced Human Resource Studies research partnership meeting, May 1.

Rau, J. (1994). Nothing succeeds like training for success. The Wall Street Journal, September 12, A16.

Rich, J.R. \& Boudreau, J.W. (1987). Effects of variability and risk in utility analysis: An empirical test and simulation. Personal Psychology, 40, 55-84.

Salwen, K.G. (1994). Fines of nearly $\$ 7.5$ million are levied after worker death at Bridgestone unit. The Wall Street Journal, April 19, A5.

Scarpello, B. \& Theeke, H.A. (1989). Human resource accounting: A measured critique. Journal of Accounting Literature, 8, 265-280.

Skousen, K.F. (1991). An introduction to the SEC. Cincinnati, OH: South-Western Publishing.

Stewart, T.A. \& Martin, M.H. (1996). Taking on the last bureaucracy: Fortune, January 15, 105.

Tichy, N. (1993). Jack Welch's lessons for success. Fortune, January 25, 86-93.

Work in America Institute (1993). Workplace innovation. Work in America. 18, 3. 


\section{ENDNOTE}

1 The calculations are depicted in the following table (assume values in millions):

\begin{tabular}{lccccc}
\hline Option & Capital & Capital Cost $@$ & $\begin{array}{c}\text { ROI } \\
\text { Profits/Capital }\end{array}$ & $\begin{array}{c}\text { EVA }=\text { Profits- } \\
\text { Capital Cost }\end{array}$ \\
\hline Maximize EVA & $\$ 1200$ & $\$ 5000$ & $\$ 900$ & $24 \%$ & $\$ 300$ \\
Maximize ROI & $\$ 600$ & $\$ 2000$ & $\$ 360$ & $30 \%$ & $\$ 240$ \\
\hline
\end{tabular}

